DOI: http://doi.org/10.46667/renbio.v14i2.527

\title{
ANÁLISE DO CONHECIMENTO DE DOCENTES NA PREVENÇÃO DE HELMINTÍASES EM ESCOLAS PÚBLICAS RURAIS/FLORESTAIS DO ACRE, BRASIL
}

\author{
ANALYSIS OF THE TEACHERS' KNOWLEDGE IN THE PREVENTION OF \\ HELMINTHIASES FROM RURAL/FOREST PUBLIC SCHOOLS \\ IN ACRE STATE, BRAZIL
}

\section{ANÁLISIS DEL CONOCIMIENTO DE PROFESORES EN PREVENCIÓN DE HELMINTIASES EN ESCUELAS PÚBLICAS RURALES/FORESTALES EN EL ESTADO DE ACRE, BRASIL}

\author{
Tuan Pedro Dias Correia ${ }^{1}$; Fernanda Bittencourt Oliveira ${ }^{2}$; Leandro Batista das Neves ${ }^{3}$; \\ Paulo Eduardo Ferlini Teixeira ${ }^{4}$; Leandro Siqueira de Souza ${ }^{5}$; Rosângela Rodrigues Silva \\ Renata Heisler Neves ${ }^{7}$; Fernanda Barbosa de Almeida da Cunha ${ }^{8}$
}

\begin{abstract}
Resumo
As helmintíases são doenças parasitárias que causam prejuízos à saúde coletiva, afetando principalmente populações mais desfavorecidas. Por isso, o objetivo do estudo foi analisar o conhecimento acerca das helmintíases de docentes $(\mathrm{n}=77)$ de escolas de áreas rurais/florestais de munícipios do Acre (Sena Madureira e Xapuri), em uma abordagem quantitativa e qualitativa. Observou-se que os professores possuem um bom conhecimento a respeito da profilaxia, mas foram verificados equívocos e lacunas com relação às formas de transmissão e aos agentes etiológicos. A educação em saúde exerce um papel fundamental na prevenção de doenças helmínticas e por isso, profissionais da educação básica, principalmente de ambientes rurais/florestais de difícil acesso, necessitam de formação continuada para atuarem como agentes promotores de saúde.
\end{abstract}

Palavras-chave: Helmintíases; Educação em Saúde; Aperfeiçoamento professional; Escolas rurais; Brasil.

${ }^{1}$ Licenciado em Ciências Biológicas - Universidade do Estado do Rio de Janeiro (UERJ) - Rio de Janeiro, RJ - Brasil. Colaborador - Laboratório de Helmintos Parasitos de Vertebrados (LHPV-IOC-FIOCRUZ) - Rio de Janeiro, RJ - Brasil. E-mail: tuan.pedro@gmail.com .

${ }^{2}$ Doutoranda em Microbiologia - Universidade do Estado do Rio de Janeiro (UERJ) - Rio de Janeiro, RJ - Brasil. Colaboradora - Laboratório de Helmintos Parasitos de Vertebrados (LHPV-IOC-FIOCRUZ) - Rio de Janeiro, RJ - Brasil. E-mail: fernandabbio@gmail.com

${ }^{3}$ Mestrado em Microbiologia - Universidade do Estado do Rio de Janeiro (UERJ) - Rio de Janeiro, RJ Brasil. Tecnologista em Saúde Pública - Laboratório de Helmintos Parasitos de Vertebrados (LHPV-IOCFIOCRUZ) - Rio de Janeiro, RJ - Brasil E-mail: 1bn@ioc.fiocruz.br

${ }^{4}$ Doutorado em Biodiversidade e Saúde - Fundação Oswaldo Cruz (FIOCRUZ) - Rio de Janeiro, RJ Brasil. Professor - Instituto Federal de Educação, Ciência e Tecnologia de Mato Grosso do Sul (IFMS) - Campus Nova Andradina - Nova Andradina, MS - Brasil. E-mail:

${ }^{5}$ Mestrando em Medicina Tropical - Fundação Oswaldo Cruz (FIOCRUZ) - Rio de Janeiro, RJ - Brasil. Colaborador - Laboratório de Helmintos Parasitos de Vertebrados (LHPV-IOC-FIOCRUZ) - Rio de Janeiro, RJ Brasil. E-mail: leandrosiqueirasouza@gmail.com

${ }^{6}$ Doutorado em Biologia Parasitária - Fundação Oswaldo Cruz (FIOCRUZ) - Rio de Janeiro, RJ - Brasil. Pesquisadora em Saúde Pública - Laboratório de Helmintos Parasitos de Vertebrados (LHPV-IOC-FIOCRUZ) Rio de Janeiro, RJ - Brasil. E-mail: rsilva@ioc.fiocruz.br

${ }^{7}$ Doutorado em Biologia Parasitária - Fundação Oswaldo Cruz (FIOCRUZ) - Rio de Janeiro, RJ - Brasil. Professora Associada - Universidade do Estado do Rio de Janeiro (UERJ) - Rio de Janeiro, RJ - Brasil. E-mail: renataheisler@gmail.com

${ }^{8}$ Doutorado em Microbiologia - Universidade do Estado do Rio de Janeiro (UERJ) - Rio de Janeiro, RJ - Brasil. Tecnologista em Saúde Pública - Laboratório de Helmintos Parasitos de Vertebrados (LHPV-IOCFIOCRUZ) - Rio de Janeiro, RJ - Brasil. E-mail: almeida@ioc.fiocruz.br 


\begin{abstract}
Helminthiases are parasitic diseases that cause damage to public health, affecting mainly the most disadvantaged populations. Therefore, the objective of the study was to analyze the knowledge about the helminthiasis of teachers $(\mathrm{n}=77)$ from schools in rural/forested areas of municipalities in Acre state (Sena Madureira and Xapuri), using a quantitative and qualitative approach. It was observed that the teachers have good knowledge about prophylaxis, but mistakes and gaps were verified regarding the forms of transmission and the etiological agents. Health education plays a fundamental role in the prevention of helminthic diseases and, therefore, basic education professionals, especially in rural/forest environments that are difficult to access, need continuing education to act as health-promoting agents.
\end{abstract}

Keywords: Helminthiases; Health education; Professional improvement; Rural schools; Brazil.

\title{
Resumen
}

Las helmintiasis son enfermedades parasitarias que causan daños a la salud pública, afectando principalmente a las poblaciones más desfavorecidas. Por tanto, el objetivo del estudio fue analizar el conocimiento sobre la helmintiasis de docentes $(\mathrm{n}=77)$ de escuelas en áreas rurales/forestales de municipios del estado de Acre (Sena Madureira y Xapuri), desde un enfoque cuantitativo y cualitativo. Se observó que los docentes tienen buenos conocimientos sobre profilaxis, pero se verificaron errores y brechas en cuanto a las formas de transmisión y los agentes etiológicos. La educación en salud juega un papel fundamental en la prevención de las enfermedades helmínticas y, por tanto, los profesionales de la educación básica, especialmente en entornos rurales/forestales de difícil acceso, necesitan educación continua para actuar como agentes promotores de la salud.

Palabras clave: Helmintiasis; Educación en salud; Mejora profesional; Escuelas rurales; Brasil.

$$
* * *
$$

\section{Introdução}

\subsection{Escolas rurais e a Educação do Campo}

As escolas rurais no Brasil são instituições de ensino que surgiram da necessidade de atender à população de assentamentos agrícolas, campos e reservas florestais, através de uma educação pensada e adaptada às características da vida no campo (SILVA JÚNIOR \& NETTO, 2011). As salas de aula geralmente são constituídas por corpo discente heterogêneo, com mais de um segmento por turma (multisseriadas) de modo a otimizar o tempo-espaço das instituições, particularmente mais autônomas para a organização de seus ambientes (FARIAS, 2015). Assim, as escolas rurais possuem calendário escolar próprio adequado com a rotina de trabalho na zona rural (ciclo agrícola), pois a agricultura familiar, muitas vezes, necessita do auxílio dos filhos desde a infância (BRASIL, 1996; RABELO, 2002 apud SOARES, 2003).

A princípio, por volta da década de 60 , a educação rural foi uma estratégia para evitar a migração da população do campo para os centros urbanos (PROENÇA \& LAMARI MAIA, 2020). Na época em questão, a visão do camponês e do rural estava constantemente associada ao arcaico e atrasado. Nesse sentido, após esforços de educadores pertencentes aos movimentos sociais de luta pela terra, como Movimento dos Trabalhadores Rurais Sem Terra (MST), e de diversas entidades filantrópicas em busca de melhorias para a população do campo, foi cunhado o termo "Educação do Campo" no Encontro Nacional de Educadores da Reforma Agrária, em 1997, que tem sido empregado desde então (FARIAS, 2015). O conceito de Educação do 
DOI: http://doi.org/10.46667/renbio.v14i2.527

Campo visa valorizar os "conhecimentos da prática social dos camponeses e enfatiza o campo como lugar de trabalho, moradia, lazer, sociabilidade e identidade, ou seja, um lugar de construção de novas possibilidades de reprodução social e de desenvolvimento sustentável" (SOUZA, 2008, p. 1090). Essa nova denominação possui grande relevância por contrapor a visão tradicional de educação rural (SOUZA, 2008). Por isso, o currículo da escola rural e a formação de professores que atuarão nessas áreas devem ser contextualizados com tais realidades locais para que seja proporcionada uma aprendizagem que respeite a identidade dessas populações (SOARES, 2003).

É importante salientar que a formação de profissionais de educação que residem em locais rurais se deve a programas que levam educação formal a essas áreas, como o Programa Nacional da Educação na Reforma Agrária (PRONERA). O programa dispunha de cursos que atendiam a diversas faixas etárias e graus de escolaridade como: Ensino Fundamental e Médio Regulares, Ensino de Jovens e Adultos (EJA) e os cursos de Ensino Médio Normal e Ensino Superior, desenvolvidos em parceria com Universidades Federais (BRASIL, 2015). A contribuição do PRONERA na formação de profissionais de educação que atuam na Educação do Campo é inegável. Contudo, o programa vem sofrendo com a ascensão de uma política que se coloca contra os movimentos sociais de luta pela terra, em uma visão limitada do ambiente rural como um local de exploração de riquezas naturais (COSTA, 2020). Prova disto é o desmonte que resultou na inviabilização do PRONERA, impactando diretamente na Educação do Campo (BORGES \& CARNEIRO, 2020).

\subsection{As helmintíases e a Educação em Saúde como estratégia de prevenção}

Na região amazônica a população do campo possui como principal atividade econômica o agroextrativismo e a criação de animais, estando em contato constante com o ambiente rural/florestal. Essas características somadas à falta de saneamento básico e acesso à água potável tornam essas populações mais suscetíveis a doenças helmínticas, causando prejuízos à saúde dessas comunidades (SOUZA et al., 2007; MARQUES et al., 2020).

As helmintíases são doenças causadas por helmintos pertencentes aos filos Platyhelminthes e Nemathelminthes e constituem um grave problema de saúde coletiva em países em desenvolvimento, incluindo o Brasil (PUSPITA et al., 2020). Suas prevalências estão intimamente ligadas à pobreza e falta de condições sanitárias, sendo muito frequentes em países tropicais e subtropicais como os da África Subsaariana, das Américas, os do leste asiático e a China (HOTEZ et al., 2020; WHO, 2020a). Dentre as helmintíases que acometem humanos, as principais são as transmitidas pelo solo: ascaridíase (Ascaris lumbricoides Linnaeus, 1758), tricuríase (Trichuris trichiura Linnaeus, 1771) e ancilostomíase (Necator americanus (Stiles, 1902) e Ancylostoma duodenale (Dubini, 1843)) que infectam cerca de $24 \%$ (>1,5 bilhões) da população mundial (HARHAY, HORTON \& OLLIARO, 2010; WHO, 2020a). Além destas, no Brasil, estão presentes outras helmintíases, como as equinococoses humanas (Echinococcus Rudolphi, 1801), a esquistossomose (Schistosoma mansoni Sambon, 1907), a estrongiloidíase (Strongyloides stercoralis (Bavay, 1876) Stiles \& Hassal, 1902), a enterobíase (Enterobius 
DOI: http://doi.org/10.46667/renbio.v14i2.527

vermicularis (Linnaeus, 1758)) e a teníase/cisticercose (Taenia solium Linnaeus, 1758 e Taenia saginata Goeze, 1782) (HARHAY, HORTON \& OLLIARO, 2010). Todas são classificadas pela Organização Mundial de Saúde (OMS) como Doenças Tropicais Negligenciadas (DTNs) que integram uma lista de 20 agravos (WHO, 2020b) com poucos incentivos à pesquisa, produção de medicamentos e controle, promovendo condições crônicas e incapacitantes (ENGELS \& ZHOU, 2020; HOTEZ et al., 2020).

Crianças, principalmente em idade escolar, são mais suscetíveis a infecções intestinais por possuírem o sistema imunológico ainda pouco estimulado e baixa preocupação com hábitos de higiene, facilitando o desenvolvimento de helmintíases que em sua grande maioria são transmitidas por via fecal-oral ou penetração cutânea, gerando déficits nutricionais e queda no rendimento escolar (KABATENDE et al., 2020; MARQUES et al., 2020). Como método de controle, prevenção e eliminação das helmintíases, a OMS preconiza: a desparasitação preventiva de crianças em idade escolar e grupos de risco por meio da administração em massa de quimioterápicos anti-helmínticos, o fornecimento de água tratada e a educação em saúde (WHO, 2020a). A quimioterapia preventiva, embora eficaz a curto prazo, não elimina o risco de reinfecções (CABADA et al., 2014; DUNN et al., 2019), podendo se relacionar com o aumento de infecções por protozoários intestinais (OLIVEIRA et al., 2020). Nesse sentido, a educação em saúde torna-se uma estratégia importante de controle e prevenção de reinfecções, pois estimula uma mudança comportamental (PALMEIRIM et al., 2018), englobando concepções de diferentes áreas da educação e da saúde, baseadas em diferentes perspectivas do modo de viver (SCHALL \& STRUCHINER, 1999), o que direciona a atuação dos profissionais nesse contexto frente à comunidade escolar.

Em áreas endêmicas, professores da educação básica desempenham papel fundamental no ensino de medidas profiláticas a respeito das helmintíases por atuarem diretamente na formação da população mais afetada que será a principal difusora deste conhecimento no ambiente domiciliar (UCHÔA et al., 2004). Contudo, as defasagens na formação desses profissionais em relação à educação em saúde e a falta de adaptação do conteúdo à realidade escolar dificultam esse processo de ensino-aprendizagem e carecem de uma abordagem pedagógica que estimule o pensamento crítico em relação à saúde coletiva (MOHR, 2002; SANTOS \& ARAÚJO, 2020), tornando esse conteúdo negligenciado em diversas ocasiões.

Este estudo tem como objetivo avaliar o conhecimento e atuação de professores de escolas públicas rurais/florestais do Acre acerca das helmintíases e suas profilaxias, uma vez que esses conteúdos integram a Base Nacional Comum Curricular (BNCC) (BRASIL, 2018) e são de grande relevância, haja vista a alta prevalência dessas infecções na região amazônica (SOUZA et al., 2007; DELFINO et al., 2016; MARQUES et al., 2020). 


\section{Procedimentos Metodológicos}

A pesquisa consistiu em um estudo transversal de caráter quantitativo-qualitativo por meio de método misto (CRESWELL, 2009; DAL-FARRA \& FETTERS, 2017) para o reconhecimento da atuação docente frente ao combate às helmintíases em áreas florestais do Acre, além de propor abordagens pedagógicas conjuntas. Foi desenvolvida entre os anos de 2018 e 2019 em dois municípios do interior do Acre: Sena Madureira e Xapuri.

\subsection{Público alvo}

O estudo avaliou professores que atuavam em escolas rurais/florestais e foi composto por setenta e sete (77) professores do $1^{\circ}$ segmento do ensino fundamental dos municípios de Sena Madureira $(n=47)$ e Xapuri $(n=30)$.

\subsection{Caracterização da área estudada}

Os municípios do Acre estão inseridos no bioma amazônico com $87 \%$ do seu território recoberto por Floresta Amazônica (ACRE, 2015) e suas populações rurais estão inseridas na floresta, desenvolvendo o agroextrativismo e caça como principais atividades para subsistência. Segundo o IBGE (s.d.), dentre os municípios do estado, Sena Madureira havia registrado o maior índice de internações por diarreia (15,2 por 1000 habitantes) e alto índice de mortalidade infantil (14,1 por 1.000 habitantes), enquanto Xapuri, por 1.000 habitantes, 2,2 internações por diarreia e 3,28 óbitos por nascidos vivos. Com relação ao esgotamento sanitário adequado, Sena Madureira e Xapuri possuíam, respectivamente, 12,5\% e 27,7\%, enquanto Rio Branco, a capital do estado, possuía $56,7 \%$ (IBGE, s.d.). Tais fatores, também expressos pelo baixo Índice de Desenvolvimento Humano (IDH) dos municípios estudados (PNUD, 2010), compõem o panorama de maior prevalência das doenças helmínticas. Ainda assim, o Índice de Desenvolvimento da Educação Básica (IDEB) de 2019 de cada município ficaram acima da média estadual de 4,8, sendo 5,7 em Sena Madureira e 5,9 em Xapuri (BRASIL, 2019), revelando resultados animadores no panorama geral do país (DEMO, SILVA \& SANTOS CRUZ, 2020).

\subsection{Coleta e análise dos dados}

Após anuência da participação voluntária dos professores, foi aplicado um questionário contendo quatro perguntas abertas para verificação do conhecimento dos professores acerca das doenças helmínticas. As perguntas, seus objetivos e respostas esperadas estão expostas no quadro 1. 
DOI: http://doi.org/10.46667/renbio.v14i2.527

Quadro 1: Informações do questionário aplicado aos docentes com as perguntas realizadas, objetivos e respostas esperadas.

\section{Perguntas}

1) $\mathrm{O}$ que são

Helmintíases?

2) Como se dá a transmissão helmintíases?

3) Quais são as principais formas de se prevenir contra as helmintíases?

4) Roer as unhas influencia quanto a adquirir helmintíases? Por quê?
Objetivos

Verificar a capacidade do docente em definir helmintíases.

Averiguar conhecimento acerca dos meios de transmissão das helmintíases.

Apurar o conhecimento a respeito das medidas profiláticas das helmintíases.

\section{Verificar a capacidade de} contextualizar a forma de transmissão através de um hábito prejudicial à saúde.

\section{Respostas esperadas}

Doenças causadas por helmintos que parasitam humanos.

Principalmente pela rota fecal-oral auxiliada pela falta de saneamento e condições precárias de higiene.

Possuindo um bom hábito de higiene (lavagem constante das mãos, unhas aparadas, etc.), filtrando ou fervendo a água de consumo e lavando bem os alimentos, não alimentando os animais domésticos com as vísceras cruas de animais caçados para subsistência.

Sim, porque a unha pode funcionar como um reservatório de matéria e conter ovos de helmintos antes dispersos no ambiente. Com isso, ovos são levados até a boca no ato de roer e entram no trato gastrointestinal.

Fonte: Os autores.

As respostas do questionário foram integralmente transcritas para planilhas de Excel (Microsoft Office Excel 2016) e submetidas ao programa MAXQDA (versão 20.0.6) visando estabelecer a frequência de cada palavra das respostas direcionando a criação de códigos de respostas por meio da ferramenta MaxDictio. Posteriormente, as respostas foram submetidas a uma nova leitura onde foi realizada a codificação. Ao final, com a ferramenta "Análise", foram gerados os gráficos da frequência dos códigos de respostas para cada pergunta.

Após aplicação do questionário, foi realizada uma palestra de conscientização sobre os riscos das helmintíases e iniciada uma discussão aberta sobre as estratégias didáticas para a abordagem da educação em saúde nas escolas rurais/florestais da região, utilizando-se da experiência dos professores participantes. 


\section{Resultados e Discussão}

\subsection{Análise do perfil e da formação dos professores}

A idade dos setenta e sete (77) professores que participaram do nosso estudo variou entre 27 e 79 anos (média de 37,95), sendo 46 mulheres e 31 homens. A área de formação incluía: Ensino Médio Normal (22); Pedagogia (21); Biologia/Ciências (7); Letras/Português (6); Educação Física (3); Geografia (3); História (3); Matemática (1); não informaram (11). Embora com formações diversas e que no primeiro momento não se relacionavam diretamente com a educação e saúde, tratavam-se de professores de escolas rurais/florestais, onde um único professor é responsável por todos os assuntos do conteúdo escolar.

A maioria dos profissionais possuem formação Normal ou Pedagogia, podendo estar relacionado ao surgimento de um dos primeiros programas de formação docente do Acre, o Programa de Formação de Professores em Nível Médio (PROFORMAÇÃO) e da Universidade Federal do Acre (UFAC), ofertando turmas para o curso de Pedagogia em cidades do interior e desempenhando um importante papel na formação docente para a Educação do Campo no Acre (SOARES, 2003).

Um aspecto interessante relacionado ao perfil de professores que lecionam nessas localidades é a formação diversa e que não possui, especificamente, conteúdos aprofundados relacionados ao processo saúde-doença (que envolve conhecimentos biológicos e sociais) (MOHR, 2009). Quanto aos conhecimentos sobre didática em saúde, Mohr (2009) discute que a formação de professores é, em muitos casos, deficiente. A formação continuada, que se dá em sua maioria em formato de palestras ou minicursos, não fornece ao professor segurança e conhecimento suficiente para desenvolver atividades de educação em saúde.

Analisando a ementa dos cursos de formação de professores, Hansen, Pedroso e Venturi (2014) constataram que a construção de conhecimentos acerca da educação em saúde sob uma perspectiva pedagógica não é proporcionada aos professores em sua formação inicial. Eles recebem o conhecimento, porém, não são capazes de alcançar resultados satisfatórios com seus discentes. Adicionalmente, tais professores exercem o papel desafiador de ministrar todas as disciplinas, além de incorporarem a educação em saúde no cotidiano dos estudantes.

Hansen, Pedroso e Venturi (2014) descrevem que existem disciplinas das diversas formações de professores que apresentam relações diretas e indiretas com educação em saúde. As disciplinas que possuem relações diretas proporcionam expressiva bagagem de conhecimento em educação em saúde por estarem relacionadas à fisiologia e anatomia humana e as doenças que acometem os seres humanos. Os autores relatam também a existência de disciplinas que se relacionam indiretamente com o ensino em saúde, por terem como objetivo desenvolver as múltiplas abordagens para o processo de aprendizagem, focando no aspecto pedagógico. Sendo assim, o real desenvolvimento do profissional apto para atuar no ensino de saúde perpassa essas diferentes disciplinas. Porém, apenas a presença de conteúdos 
DOI: http://doi.org/10.46667/renbio.v14i2.527

relacionados à educação em saúde na ementa não garante a qualidade do ensino (HANSEN, PEDROSO \& VENTURI, 2014), sendo necessário sua contextualização à realidade de trabalho desses futuros profissionais.

A educação em saúde, quando abordada de forma eficaz e contextualizada na formação docente, pode resultar no envolvimento da comunidade, na aquisição de novas habilidades que promovam a prevenção de doenças e na construção de cidadãos críticos e questionadores sobre a sociedade e seus estilos de vida (IERVOLINO \& PELICIONI, 2005).

\subsection{Análise do questionário}

As respostas para a pergunta 1 ( $\mathrm{O}$ que são helmintíases?) demonstraram grande frequência das palavras "doenças" (30) e "vermes" (30), seguida de "parasitos" (26) e "bactérias" (11), conforme o exposto no gráfico 1. A palavra "doença" é bem esperada, uma vez que consiste em um termo bastante generalista, conferindo segurança ao entrevistado em utilizá-la.

Siqueira e colaboradores (2016) observaram em seu trabalho com professores e alunos da rede estadual de ensino do Rio de Janeiro que metade dos participantes associou verminoses/helmintoses aos vermes, além de citarem a sujeira como meio de transmissão. Ao empregar os termos "vermes", "parasitos" e "bactérias", os docentes tentam sair da generalização e definir o agente causador da doença. Considerando que estes termos, com exceção de "bactérias", constituem uma classificação correta e foram empregados por participantes diferentes, totalizou-se o uso por $72,7 \%$ dos professores, percentual próximo $(77,4 \%)$ ao encontrado por Gonçalves, Vasco-dos-Santos e Nunes (2020) com docentes de escolas rurais da Bahia, indicando uma consistência no conhecimento destes profissionais. Ainda, Sá-Silva e colaboradores (2010), em seu trabalho com docentes de uma escola municipal de São Luís (MA), verificou que os professores associaram as helmintíases com agentes parasitários similares as respostas obtidas neste estudo, demonstrando um domínio, ainda que incompleto, dos agentes patógenos dessas infecções. 
DOI: http://doi.org/10.46667/renbio.v14i2.527

Gráfico 1: Frequência de palavras utilizadas pelos docentes do Acre em resposta à pergunta "O que são helmintoses?"

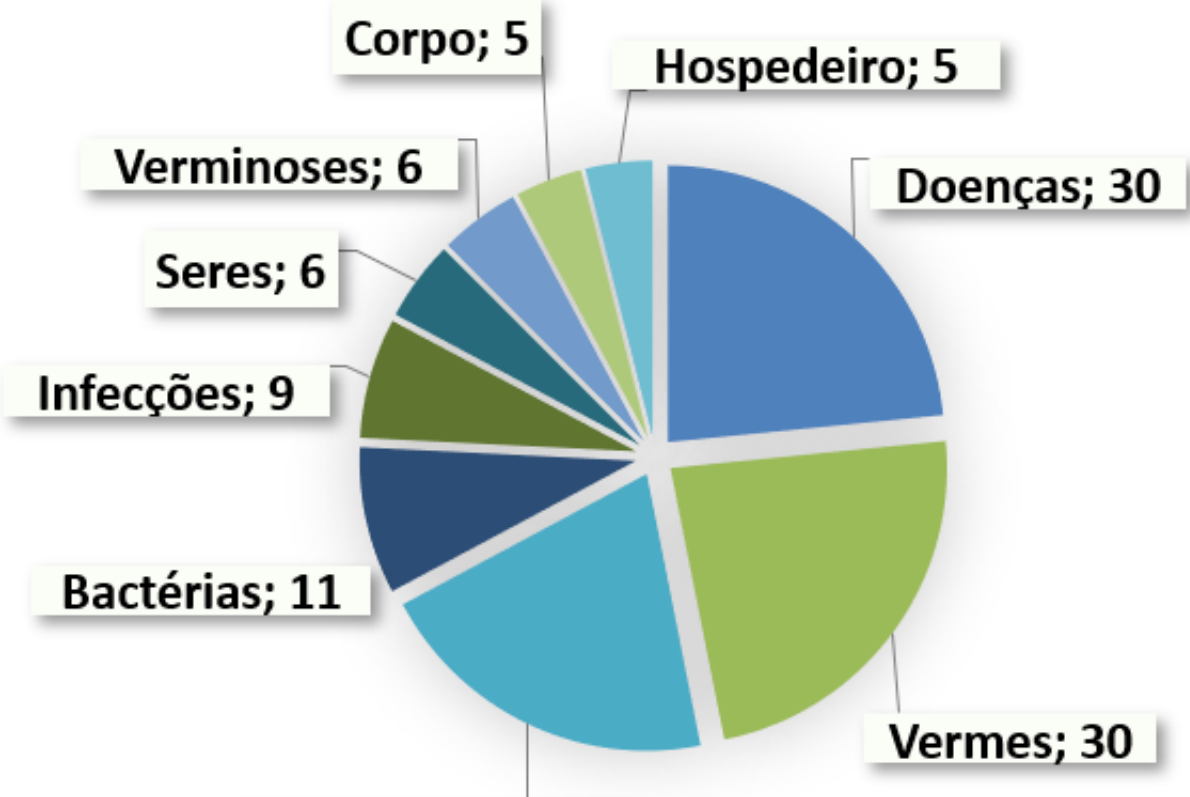

\section{Parasitos; 26}

Legenda: Os números representam a quantidade de respostas contempladas pelas categorias. Fonte: Os autores.

$\mathrm{Na}$ tentativa de definir os agentes causadores dessas infecções alguns erros foram observados nas respostas dadas conforme é exemplificado nas seguintes respostas:

São vermes, vírus que se desenvolvem nos seres humanos. [D17-2018, grifo nosso]

São doenças causadas por vírus ou bactérias existentes nos ambientes e nos alimentos. [D19-2018, grifo nosso]

São bactérias causadoras de doenças. [D20-2018, grifo nosso]

Bactérias que prejudicam o funcionamento do nosso corpo. [D22-2019, grifo nosso]

Os grifos evidenciam a utilização dos termos "bactérias" e "vírus" de maneira errônea pelos docentes, uma vez que as helmintíases são causadas por nematoides e platelmintos (REY, 2008). Esse emprego equivocado também foi verificado por Matozinhos (2017), onde a autora sugeriu que o senso comum pode gerar uma possível associação entre os organismos por serem frequentemente patogênicos. 
DOI: http://doi.org/10.46667/renbio.v14i2.527

Para a pergunta 2 (Como se dá a transmissão das helmintoses?), o aparecimento das categorias mais frequentes de respostas (gráfico 2) também foram verificadas em outros estudos sobre o conhecimento acerca da transmissão das helmintoses (BATH et al., 2010; MORAES NETO et al., 2010; MONROE et al., 2013; NASR et al., 2013; GONÇALVES, VASCO-DOSSANTOS \& NUNES, 2020). Destaca-se a categoria "alimentos mal higienizados" sendo também a mais prevalente na pesquisa de Gonçalves, Vasco-dos-Santos e Nunes (2020) com $55,5 \%$ de frequência e na de Nasr e colaboradores (2013) com 24,2\%, sugerindo a consolidação desse meio de transmissão no conhecimento popular. Apesar disso, uma vez que o público analisado é formado por professores considerava-se conveniente que outras formas de transmissão das helmintoses apresentassem frequência mais elevada, como a "contaminação fecal", "falta de saneamento básico" e "andar descalço", divergindo dos resultados de Monroe e colaboradores (2013) com o grupo amostral de professores de São Luís (MA). Tal fato aponta para uma defasagem a ser trabalhada, principalmente por se tratar de um problema característico do ambiente florestal/rural acreano (SOUZA et al., 2007; DELFINO et al., 2016) e provavelmente a principal forma de transmissão das helmintíases.

Gráfico 2: Frequência de palavras utilizadas pelos docentes de escolas rurais/florestais do Acre em resposta à pergunta "Como se dá a transmissão das helmintoses?"



Legenda: Os números representam a quantidade de respostas contempladas pelas categorias. Fonte: Os autores. 
DOI: http://doi.org/10.46667/renbio.v14i2.527

Nos exemplos abaixo é possível notar a associação da poluição hídrica pela falta de saneamento básico realizada por alguns dos docentes:

Não lavar as mãos antes das refeições, andar descalço, não ter esgoto adequado, poluição das águas por fezes. [D4-2018, grifo nosso]

Por alimentos mal cozidos, verduras e frutas mal lavadas, falta de higiene pessoal e do ambiente, falta de saneamento, água contaminada. [D13-2019, grifo nosso]

Não obstante, é possível notar que pelas categorias mais frequentes e as respostas acima que há uma forte relação entre o modo de transmissão e a as formas de prevenção, assunto abordado na pergunta 3 e com as frequências de respostas demonstradas no gráfico 3.

Gráfico 3: Frequência de palavras utilizadas pelos docentes em resposta à pergunta "Quais são as principais formas de se prevenir contra uma parasitose?"

Lavar bem os alimentos

Lavar as mãos

Ter uma boa higiene pessoal Água filtrada/fervida

Cozinhar bem os alimentos

Não andar descalço

Cuidado com alimentação

Limpar/Aparar as unhas

Abrangentes/Não específicas

Consultando um médico

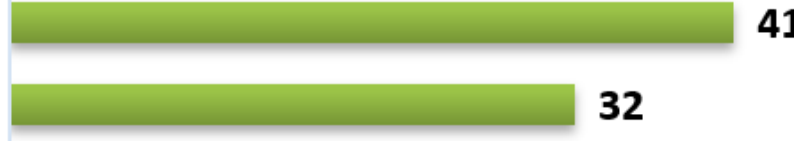

29

28
18

16

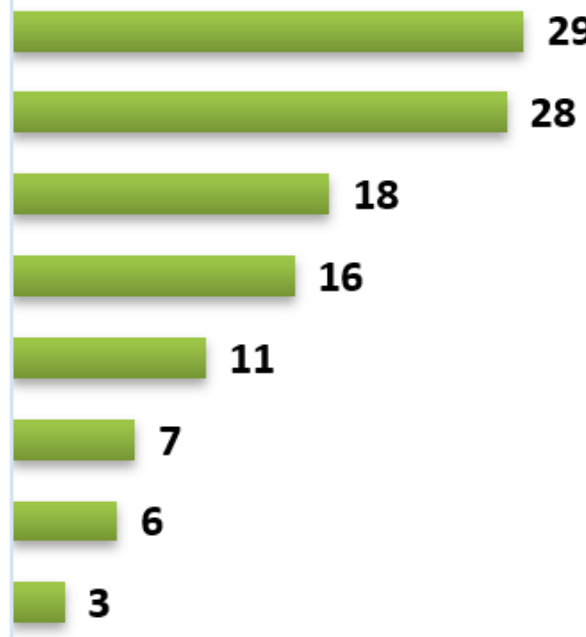

Legenda: Os números representam a quantidade de respostas contempladas pelas categorias. Fonte: Os autores.

As respostas da pergunta 3 (Quais são as principais formas de se prevenir contra uma helmintíase?) revelaram que as respostas mais frequentes estão relacionadas ao cuidado com os alimentos e ao cuidado pessoal. A preocupação de lavar bem os alimentos, principalmente hortaliças, é um hábito extremamente importante na prevenção de doenças helmínticas, pois sua forma de produção (irrigação, acesso da área plantada por animais, etc.) pode desempenhar um papel importante na difusão de enteroparasitoses, inclusive as causadas por helmintos (MEDEIROS, OLIVEIRA \& MALAGA, 2019). A lavagem de mãos e alimentos é um método profilático de grande importância, sendo uma das respostas mais frequentes em estudos a 
DOI: http://doi.org/10.46667/renbio.v14i2.527

respeito de conhecimentos sobre doenças helmínticas, seja com profissionais de ensino (GONÇALVES, VASCO-DOS-SANTOS \& NUNES, 2020), alunos (BIERI et al., 2013) ou a população em geral (BATH et al, 2010; NASR et al, 2013). Atualmente, devido à pandemia de COVID-19, a lavagem das mãos ganhou um destaque ainda maior, podendo impactar também na redução de outras infecções negligenciadas, inclusive as helmínticas (HOTEZ, FENWICK \& MOLYNEUX, 2021).

As respostas que demonstraram preocupação com o tratamento da água antes do consumo - "água filtrada ou fervida" - possuem um notório papel na manutenção da saúde de moradores de região rural, já que o consumo da água de rios e igarapés em locais onde não há saneamento básico é um dos maiores contribuintes para a prevalência de helmintoses nessas regiões (SOUZA et al., 2007). É interessante ressaltar os relatos da importância do andar calçado, pois a presença de ancilostomídeos infectando humanos é uma realidade nessa região (SOUZA et al., 2007). Porém, a frequência de aparição dessa medida profilática ainda é baixa $(20,8 \%)$ se levada em comparação ao nível de formação dos participantes com os de Moraes Neto e colaboradores (2010), que observaram uma frequência de $37 \%$ ao trabalhar com população de baixa renda de Campos dos Goytacazes (RJ). Adicionalmente, outra categoria evidente foi "cozinhar bem os alimentos". A cocção de carnes, principalmente bovina e suína, é uma das principais medidas profiláticas para o complexo teníase-cisticercose. Ainda que sua prevalência na região norte seja baixa (ROSSI et al., 2014), não deixa de ser uma prática importante para a manutenção da saúde.

Por sua vez, as categorias de respostas com relação à pergunta 4 (Roer as unhas influencia quanto a adquirir helmintoses? Por quê?) e suas frequências, estão demonstradas no gráfico 4.

Gráfico 4: Frequência de palavras utilizadas pelos docentes do Acre em resposta à pergunta "Roer as unhas influência quanto a adquirir helmintoses? Por quê?"

Acúmulo de sujeira

Concentração de vermes/parasitos

Abrigo de fungos e bactérias

Por levar as mãos à boca/ingestão

Micróbios/Micro-organismos

Não sei

Presença de ovos de parasitos

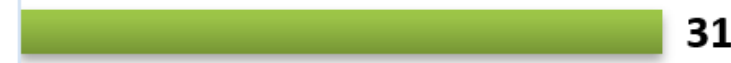

24
12

8

6

3

3

Legenda: Os números representam a quantidade de respostas contempladas pelas categorias.

Fonte: Os autores. 
DOI: http://doi.org/10.46667/renbio.v14i2.527

Setenta e quatro (74) professores $(96,1 \%)$ responderam que o ato de roer unha contribui para o desenvolvimento de infecções helmínticas e apenas $3(3,9 \%)$ responderam "não sei". Resultados semelhantes foram encontrados por Tome e colaboradores (2005), onde cerca de $85,88 \%$ das professoras da educação infantil afirmaram que esse hábito influi sobre a aquisição de helmintoses. Grande parte das respostas associou o "acúmulo de sujeira", categoria de maior frequência, à presença de agentes patógenos, conforme exemplificado em algumas respostas abaixo:

Sim, Muitas vezes as unhas escondem sujeiras embaixo, quando entram em contato com a boca esses parasitos entram no organismo. [D08-2018, grifo nosso]

Sim, porque a sujeira é acumulada nas unhas e ao roer pode contrair parasitoses. [D18-2018, grifo nosso]

Sim, porque embaixo das unhas pode existir sujeira, onde os parasitos podem estar. [D15-2019, grifo nosso]

As respostas positivas seguiam explicando sobre roer as unhas e se infectar através da ingestão da sujeira que se acumula entre unha e o dedo. Tal resposta relaciona-se bastante ao conhecimento popular sobre o desenvolvimento de helmintoses, sendo também observada em outros trabalhos (NASR et al., 2013; SIQUEIRA et al., 2016). Apenas 3 (3,9\%) docentes associaram o hábito de roer unhas com a possível presença de ovos de helmintos nelas, consistindo na resposta mais completa sobre relação desse hábito à aquisição de helmintoses:

Sim, pois com a manipulação de areia e outras substâncias, observamos que ovos de parasitos podem ficar sob a unha e ser ingeridos ao roê-los. [D052019, grifo nosso]

Sim, porque muitas vezes as pessoas entram em contato com algo contaminado e os ovos ficam alojados nas unhas. [D13-2019, grifo nosso]

Sim, porque as unhas podem estar contaminadas com sujeiras e ovos de parasitas. [D44-2019, grifo nosso]

As respostas não só demonstram a correta relação entre o hábito de roer unha com a aquisição de helmintíases, mas também um conhecimento acerca das formas evolutivas dos helmintos.

No debate aberto, após a explanação teórica sobre os perigos das helmintíases, suas vias de transmissão e medidas profiláticas, os docentes conseguiram reconhecer as variáveis presentes no ambiente em que vivem e lecionam, podendo utilizá-las em suas aulas de educação em saúde. Essa compreensão é de extrema importância e vai de encontro ao conceito de One Health (traduzido do inglês como "Saúde Única") que fala da "inseparabilidade da saúde humana, animal e ambiental por meio de uma visão unificada de cuidados de saúde" (MACEDO COUTO \& BRANDESPIM, 2020, p. 83), que promove uma abordagem mais contextualizada com o cotidiano do aluno. Além disso, foram discutidas técnicas ativas de 
DOI: http://doi.org/10.46667/renbio.v14i2.527

ensino para a maximização do aprendizado sobre as helmintíases, compreendendo que na prática de uma sala de aula multisseriada as dinâmicas de ensino já demandam muito tempo de aula. Como sugestão coletiva, o uso de ensino lúdico se mostrou uma estratégia interessante a ser trabalhada, além de já apresentarem resultados positivos para educação em saúde (GURGEL et al., 2017). Monroe e colaboradores (2013) coloca a escola com uma agência de saúde, propícia para a aprendizagem da profilaxia das helmintíases e relata a importância dos professores como agentes promotores da saúde.

Por isso, a importância da realização desse estudo se baseia na necessidade de compreensão do conhecimento prévio dos professores acerca das doenças helmínticas e assim poder detectar as defasagens, direcionando um trabalho de reforço e formação continuada a estes que atuam diretamente em áreas endêmicas e de difícil acesso.

\section{Considerações finais}

De modo geral, os docentes apresentaram um bom conhecimento acerca das medidas profiláticas, contudo equívocos relacionados aos agentes de transmissão e carências em relação às vias de transmissão foram verificados. Nesse sentido, professores da educação, principalmente de áreas endêmicas, necessitam de formação inicial, em serviço e continuada contextualizada à realidade da educação no campo para atuarem no combate das infecções helmínticas através da educação em saúde.

É indubitável que avanços foram alcançados progressivamente nos últimos anos na formação do professor voltado à Educação do Campo. Todavia, o crescente sucateamento da educação pela falta de incentivo e cortes nos programas de educação do campo tendem a causar a diminuição da qualidade de vida destas populações.

Vale ressaltar que a educação em saúde é uma forte aliada na prevenção de diversas doenças por meio da formação de hábitos saudáveis de higiene e ensino de medidas profiláticas, mas necessita estar associada ao desenvolvimento de políticas públicas no âmbito social, animal e ambiental (One Health) para uma efetiva promoção da saúde.

\section{Referências}

ACRE. Acre é parte da maior área de florestas naturais do Brasil. 2015. Disponível em: https://agencia.ac.gov.br/acre-e-parte-da-maior-area-de-florestas-naturais-do-brasil/. Acesso em: 28 jan. 2021.

BATH, J. L.; ENEH, P. N., BAKKEN, A. J.; KNOX, M. E.; SCHIEDT, M. D.; CAMPBELL, J. M. The impact of perception and knowledge on the treatment and prevention of intestinal worms in the Manikganj district of Bangladesh. The Yale journal of biology and medicine, v. 83, n. 4, p. 171-184, 2010. Disponível em:

https://www.ncbi.nlm.nih.gov/pmc/articles/PMC3002153/. Acesso em: 07 fev. 2021. 
DOI: http://doi.org/10.46667/renbio.v14i2.527

BIERI, F. A.; YUAN, L. P.; LI, Y. S. et al. Development of an educational cartoon to prevent worm infections in Chinese schoolchildren. Infectious Diseases of Poverty, v. 29, n. 2, 2013. https://doi.org/10.1186/2049-9957-2-29

BORGES, G. M.; CARNEIRO, M. E. O Programa Nacional da Educação na Reforma Agrária - PRONERA em "desmonte": 20 anos de lutas e conquistas ameaçados pelo elitismo fundiário no cenário de 2016 a 2020. Revista Brasileira de Educação no Campo, v. 5, e10501, 2020. http://dx.doi.org/10.20873/uft.rbec.e10501

BRASIL. Lei no 9.394, de 20 de dezembro de 1996. Estabelece as diretrizes e bases da educação nacional. Diário Oficial da União, Brasília, dez. 1996. Disponível em: http://www.planalto.gov.br/ccivil_03/leis/L9394.htm. Acesso em: 02 jan. 2020.

BRASIL. Relatório da II Pesquisa Nacional sobre a Educação na Reforma Agrária - II PNERA. Brasília, jun. 2015. Disponível em: http://www.ipea.gov.br/portal/index.php?option=com_content \&view=article\&id=25640. Acesso em: 29 maio 2021.

BRASIL. Base Nacional Comum Curricular (BNCC). 2018. Disponível em: http://basenacionalcomum.mec.gov.br/images/BNCC_EI_EF_110518_versaofinal_site.pdf. Acesso em: 31 dez. 2019.

BRASIL. IDEB - Resultados e Metas. 2019 Disponível em: http://ideb.inep.gov.br/resultado/. Acesso em: 28 jan. 2021.

CABADA, M. M.; LOPEZ, M.; ARQUE, E.; CLINTON WHITE, A. Prevalence of soiltransmitted helminths after mass albendazole administration in an indigenous community of the Manu jungle in Peru. Pathogens and global health, v. 108, n. 4, p. 200-205, 2014. https://doi.org/10.1179/2047773214Y.0000000142

COSTA, A. C. M. Educação do campo e a necessária superação da dualidade rural e urbana. Revista Em Extensão, p. 92-102, 2020. https://doi.org/10.14393/REE-2020-54375

CRESWELL, J. W. Research design: qualitative, quantitative and mixed methods approaches. Los Angeles: Sage, 2009.

DAL-FARRA, R. A.; FETTERS, M. D. Recentes avanços nas pesquisas com métodos mistos: aplicações nas áreas de educação e ensino. Acta Scientiae, v. 19, n. 3, p. 466-492, 2017. Disponível em: http://www.periodicos.ulbra.br/index.php/acta/article/view/3116. Acesso em: 07 fev. 2021.

DELFINO, B. M; CAMPOS, R. G.; PEREIRA, T. M.; MANTOVANI, S. A.; OLIARTGUZMÁN, H.; MARTINS, A. C.; BRAÑA, A. M.; BRANCO, F. L.; FILGUEIRA-JÚNIOR, J. A.; SANTOS, A. P.; ARAÚJO, T. S.; OLIVEIRA, C. S.; RAMALHO, A. A.; MUNIZ, P. T.; CODEÇO, C. T.; SILVA-NUNES, M. Evolution of socioeconomic conditions and its relation to spatial-temporal changes of giardiasis and helminthiasis in amazonian children. EcoHealth, v. 13, n. 4, p. 743-760, 2016. https://doi.org/10.1007/s10393-016-1167-z 
DOI: http://doi.org/10.46667/renbio.v14i2.527

DEMO, P.; SILVA, R. A.; SANTOS CRUZ, J. A. Sinalizações das escolas e municípios no contexto do IDEB 2019: tentativa preliminar de leitura do IDEB-2019. Temas em Educação e Saúde, v. 16, n. 2, p. 630-647, 2020. https://doi.org/10.26673/tes.v16i2.14210

DUNN, J. C.; BETTIS, A. A.; WYINE, N. Y.; LWIN, A. M. M.; TUN, A.; MAUNG, N. S.; ANDERSON, R. M. Soil-transmitted helminth reinfection four and six months after mass drug administration: results from the delta region of Myanmar. PLoS Neglected Tropical Diseases, v. 13, n. 2, e0006591, 2019. https://doi.org/10.1371/journal.pntd.0006591

ENGELS, D.; ZHOU, X. N. Neglected tropical diseases: an effective global response to local poverty-related disease priorities. Infectious Diseases of Poverty, v. 9, n. 1, 10, 2020. https://doi.org/10.1186/s40249-020-0630-9

FARIAS, A. A. Organização da educação do campo no Acre: classes multisseriadas e a questão do acompanhamento pedagógico. 2015. 84 f. Dissertação (Mestrado Profissional em Gestão e Aplicação da Educação Pública) - Faculdade de Educação, Universidade Federal de Juiz de Fora, Juiz de Fora. Disponível em:

http://repositorio.ufjf.br:8080/jspui/bitstream/ufjf/2578/1/adrianadearaujofarias.pdf. Acesso em: 14 maio 2020.

GONÇALVES, M. T. V.; VASCO-DOS-SANTOS, D. R.; NUNES, E. S. Representações da tríplice escolar sobre parasitoses intestinais na zona rural de Paulo Afonso - Bahia. Revista SUSTINERE, v. 8, n. 1, p. 66-84, 2020. https://doi.org/10.12957/sustinere.2020.50649

GURGEL, S. S.; TAVEIRA, G. P.; MATIAS, E. O.; PINHEIRO, P. N. C.; VIEIRA, N. F. C.; LIMA, F. E. T. Jogos educativos: recursos didáticos utilizados na monitoria de educação em saúde. REME: Revista Mineira de Enfermagem, v. 21, e1016, 2017.

https://doi.org/10.5935/1415-2762.20170026

HANSEN, K. S.; PEDROSO, I.; VENTURI, T. A educação em saúde na formação inicial docente: análises iniciais de um curso de Biologia e um de Pedagogia. Revista da SBEnBio, $\mathrm{n}^{\mathrm{o}}$ 7, V Enebio e II Erebio Regional 1, Out., 2014. Disponível em: https://www.academia.edu/26660720/A_EDUCA\%C3\%87\%C3\%830_EM_SA\%C3\%9ADE NA_FORMA\%C3\%87\%C3\%830_INICIAL_DOCENTE_AN\%C3\%81LISES_INICIAIS DE_UMCURSO_DE_BIOLOGIA_E_UM_DE_PEDAGOGIA. Acesso em 29 maio 2021.

HARHAY, M. O.; HORTON, J. e OLLIARO, P. L. Epidemiology and control of human gastrointestinal parasites in children. Expert Review of Anti-infective Therapy, v. 8, n. 2, p. 219-234, 2010. https://doi.org/10.1586/eri.09.119

HOTEZ, P. J.; AKSOY, S.; BRINDLEY, P. J.; KAMHAWI, S. What constitutes a neglected tropical disease?. PLoS Neglected Tropical Diseases, v. 14, n. 1, e0008001, 2020. https://doi.org/10.1371/journal.pntd.0008001

HOTEZ, P. J.; FENWICK, A.; MOLYNEUX, D. The new COVID-19 poor and the neglected tropical diseases resurgence. Infectious Diseases of Poverty, v. 10, n. 10, 2021. https://doi.org/10.1186/s40249-020-00784-2 
DOI: http://doi.org/10.46667/renbio.v14i2.527

IERVOLINO, S. A.; PELICIONI, M. C. Capacitação de professores para a promoção e educação em saúde na escola: relato de uma experiência. Revista Brasileira de Crescimento e Desenvolvimento Humano, v. 15, n. 2, p. 99-110, 2005. Disponível em:

http://pepsic.bvsalud.org/scielo.php?script=sci_arttext\&pid=S010412822005000200011\&lng=pt\&nrm=iso. Acesso em: 29 maio 2021.

INSTITUTO BRASILEIRO DE GEOGRAFIA E ESTATÍSTICA (IBGE). s. d. Disponível em:

https://cidades.ibge.gov.br/brasil/sintese/ac?indicadores=29171,25207,47001,60032,30279,60 030. Acesso em: 28 jan. 2021.

KABATENDE, J.; MUGISHA, M.; NTIRENGANYA, L.; BARRY, A.; RUBERANZIZA, E.; MBONIGABA, J. B.; BERGMAN, U.; BIENVENU, E.; AKLILLU, E. Prevalence, intensity, and correlates of soil-transmitted helminth infections among school children after a decade of preventive chemotherapy in Western Rwanda. Pathogens, v. 9, n. 12, 1076, 2020. https://doi.org/10.3390/pathogens9121076

MACEDO COUTO, R.; BRANDESPIM, D. F. A review of the One Health concept and its application as a tool for policy-makers. International Journal of One Health, v. 6, n. 1, p. 83-89, 2020. https://doi.org/10.14202/IJOH.2020.83-89

MARQUES, R. C.; BERNARDI, J.; DOREA, C. C.; DÓREA, J. G. Intestinal parasites, anemia and nutritional status in young children from transitioning Western Amazon.

International journal of environmental research and public health, v. 17, n. 2, 577, 2020. https://doi.org/10.3390/ijerph17020577

MATOZINHOS, C. R. O ensino de verminoses para alunos cegos do ensino fundamental com a utilização de materiais didáticos tridimensionais. 2017. 149 f. Dissertação (Mestrado em Ensino de Ciências) - Instituto de Ciências Exatas e Biológicas, Universidade Federal de Ouro Preto, Ouro Preto. Disponível em:

https://www.repositorio.ufop.br/handle/123456789/9530. Acesso em: 06 fev. 2021.

MOHR, A. A natureza da educação em saúde no ensino fundamental e os professores de ciências. 2002. 410 f. Tese (Doutorado em Educação) - Centro de Ciências da Educação, Universidade Federal de Santa Catarina, Florianópolis. Disponível em: https://repositorio.ufsc.br/handle/123456789/83375. Acesso em: 10 jun. 2020.

MOHR, A. Educação em saúde na escola: panorama e questionamentos a partir de depoimentos de professores de Ciências de Florianópolis. In: SELLES, S. E. et al. (Org.). Ensino de biologia: histórias, saberes e práticas formativas. Uberlândia: EDUFU, 2009

MONROE, N. B.; LEITE, P. R. R.; SANTOS, D. N.; SÁ-SILVA, J. R. O tema transversal saúde e o ensino de ciências: representações sociais de professores sobre as parasitoses intestinais. Investigações em Ensino de Ciências, v. 18, n. 1, p. 7-22, 2013. Disponível em: https://www.if.ufrgs.br/cref/ojs/index.php/ienci/article/view/146/101. Acesso em: 06 fev. 2021.

MORAES NETO, A. H. A.; PEREIRA, A. P. M. F.; ALENCAR, M. L. et al. Prevalence of intestinal parasites versus knowledge, attitudes, and practices of inhabitants of low-income 
DOI: http://doi.org/10.46667/renbio.v14i2.527

communities of Campos dos Goytacazes, Rio de Janeiro State, Brazil. Parasitology

Research, v. 107, p. 295-307, 2010. https://doi.org/10.1007/s00436-010-1861-7

MEDEIROS, F. A.; OLIVEIRA, T. R.; MALAGA, S. M. R. Segurança dos alimentos: influência sazonal na contaminação parasitária em alface (Lactuca sativa L.) comercializada em feiras livres de Belém, Pará. Brazilian Journal of Food Technology, v. 22, e2018205, 2019. https://doi.org/10.1590/1981-6723.20518

NASR, N. A.; AL-MEKHLAFI, H. M.; AHMED, A.; ROSLAN, M. A.; BULGIBA, A. Towards an effective control programme of soil-transmitted helminth infections among Orang Asli in rural Malaysia. Part 2: Knowledge, attitude, and practices. Parasites \& Vectors, v. 6, n. 28, 2013. https://doi.org/10.1186/1756-3305-6-28

OLIVEIRA, Y. L.; OLIVEIRA, L. M.; OLIVEIRA, Y. L. M.; NASCIMENTO, A. M.; LA CORTE, R.; GERALDI, R. M.; BARBOSA, L.; GAZZINELLI-GUIMARÃES, P. H.; FUJIWARA, R. T., BUENO L. L.; DOLABELLA, S. S. Changes in the epidemiological profile of intestinal parasites after a school-based large-scale treatment for soil-transmitted helminths in a community in northeastern Brazil: epidemiological profile after large-scale school-based treatment for STH. Acta Tropica, v. 202, 105279, 2020.

https://doi.org/10.1016/j.actatropica.2019.105279

PALMEIRIM, M. S.; OUATTARA, M.; ESSÉ, C. et al. Are schoolchildren less infected if they have good knowledge about parasitic worms? A case study from rural Côte d'Ivoire. BMC Public Health, v. 18, n. 951, 2018. https://doi.org/10.1186/s12889-018-5776-z

PROENÇA, N. S.; LAMARI MAIA, L. B. Desafios e conquista da educação no campo.

Revista Científica Eletrônica de Ciências Aplicadas da FAIT, n. 2, nov. 2020. Disponível em:

http://www.fait.revista.inf.br/imagens_arquivos/arquivos_destaque/OVXqLRc5JkGeMa6_20 20-12-14-17-19-11.pdf. Acesso em: 29 maio 2021.

PROGRAMA DAS NAÇÕES UNIDAS PARA O DESENVOLVIMENTO (PNUD).

Ranking IDHM Municípios 2010. 2010. Disponível em:

https://www.br.undp.org/content/brazil/pt/home/idh0/rankings/idhm-municipios-2010.html.

Acesso em: 14 jan. 2021.

PUSPITA, W. L.; KHAYAN, K.; HARIYADI, D.; ANWAR, T.; WARDOYO, S.; IHSAN, B. M. Health education to reduce helminthiasis: deficits in diets in children and achievement of students of elementary schools at Pontianak, West Kalimantan. Journal of parasitology research, v. 2020, 4846102, 2020. https://doi.org/10.1155/2020/4846102

REY, L. Parasitologia. 4 ed. Rio de Janeiro: Guanabara Koogan, 2008.

ROSSI, G. A. M.; GRISÓLIO, A. P. R.; PRATA, L. F.; BURGUER, K. P.; HOPPE, E. G. L. Situação da cisticercose bovina no Brasil. Semina: Ciências Agrárias, v. 35, n. 2, p. 927-938, 2014. https://doi.org/10.5433/1679-0359.2014v35n2p927 
DOI: http://doi.org/10.46667/renbio.v14i2.527

SÁ-SILVA, J. R.; PORTO, M. J. F.; SOUSA, C. E. B; ALMEIDA, F. V. P. Escola, educação em saúde e representações sociais: problematizando as parasitoses intestinais. Pesquisa em Foco, v.18, n.1, p. 82-95, 2010. https://doi.org/10.18817/pef.v18i1.325

SANTOS, E.; ARAÚJO, M. Implicações de um processo formativo de professores mediado por filmes, na constituição de uma visão ampliada de saúde. Revista Insignare Scientia RIS, v. 3, n. 5, p. 517-539, 2020. https://doi.org/10.36661/2595-4520.2020v3i5.11902

SCHALL, V.; STRUCHINER, M. Educação em saúde: novas perspectivas. Cadernos de Saúde Pública, v. 15, supl. 2, p. S4-S6, 1999. http://dx.doi.org/10.1590/S0102$\underline{311 X 1999000600001}$

SILVA JÚNIOR, A. F.; NETTO, M. B. Por uma educação do campo: percursos históricos e possibilidades. Entrelaçando - Revista Eletrônica de Culturas e Educação, n. 3, p. 45-60, 2011. Disponível em:

https://www2.ufrb.edu.br/revistaentrelacando/component/phocadownload/category/119?down load=125. Acesso em: 15 nov. 2020.

SIQUEIRA, M. P.; AZEVEDO, E. P.; ALMEIDA, E. M. de; MATOS, J. S.; RODRIGUES, A. R.; SCARABELLI, S. C.; PILOTTO, T. P.; FREITAS, J. T. de; BARBOSA, A. S.; MATTOS, D. P. B. G. de; BASTOS, O. M. P.; UCHÔA, C. M. A. Conhecimentos de escolares e funcionários da rede pública de ensino sobre as parasitoses intestinais. Revista do Instituto Adolfo Lutz, v. 75, 1711, 2016. Disponível em:

https://pesquisa.bvsalud.org/portal/resource/pt/biblio-835643. Acesso em: 08 fev. 2021.

SOARES, J. R. Educação Rural no Projeto de assentamento Colibri em Rio Branco/AC Um Estudo de Caso. 2003. 122 f. Dissertação (Mestrado em Educação) - Instituto de PósGraduação em Educação, Universidade Federal do Rio de Janeiro, Rio de Janeiro. Disponível em: http://www.latec.ufrj.br/monografias/2003_Jailene_Soares.pdf. Acesso em: 05 set. 2020.

SOUZA, E. A.; SILVA-NUNES, M.; MALAFRONTE, R. S.; MUNIZ, P. T.; CARDOSO, M. A.; FERREIRA, M. U. Prevalence and spatial distribution of intestinal parasitic infections in a rural Amazonian settlement, Acre State, Brazil. Cadernos de Saúde Pública, v. 23, n. 2, p. 427-434, 2007. https://doi.org/10.1590/S0102-311X2007000200019

SOUZA, M. A. de. Educação do campo: políticas, práticas pedagógicas e produção científica. Educação \& Sociedade, v. 29, n. 105, p. 1089-1111, 2008. https://doi.org/10.1590/S0101-73302008000400008

TOME, R. O.; SERRANO, A. C. M.; NUNES, C. M.; PERRI, S. H. V.; BRESCIANI, K. D. $\mathrm{S}$. Inquérito epidemiológico sobre conceitos de zoonoses parasitárias para professores de escolas municipais do ensino infantil de Araçatuba-SP. Revista Ciência em Extensão, v. 2, n. 1, p. 1-11, 2005. Disponível em:

https://ojs.unesp.br/index.php/revista_proex/article/view/183. Acesso em: 09 fev. 2021.

UCHÔA, C. M. A.; SERRA, C. M. B.; MAGALHÃES, C. M.; SILVA, R. M. M.;

FIGLIUOLO, L. P.; LEAL, C. A.; MADEIRA, M. F. Educação em saúde: ensinando sobre a leishmaniose tegumentar Americana. Cadernos de Saúde Pública, v. 20, n. 4, p. 935-941, 2004. https://doi.org/10.1590/S0102-311X2004000400007 
DOI: http://doi.org/10.46667/renbio.v14i2.527

VENTURI, T.; PEDROSO, I.; MOHR, A. Educação em saúde na escola a partir de uma perspectiva pedagógica: discussões acerca da formação de professores. In: ENCONTRO REGIONAL SUL DE ENSINO DE BIOLOGIA (EREB-SUL), 6., 2013; SEMANA ACADÊMICA DE CIÊNCIAS BIOLÓGICAS: a docência em biologia: da formação inicial à formação continuada tecendo CTSA,16., 2013, Santo Ângelo/RS. Anais... Santo Angelo/RS, 2013. Disponível em:

http://san.uri.br/sites/anais/erebio2013/comunicacao/13437_130_Tiago_Venturi.pdf. Acesso em 29 maio 2021.

WORLD HEALTH ORGANIZATION (WHO). Soil-transmitted helminth infections. 2020a. Disponível em: https://www.who.int/news-room/fact-sheets/detail/soil-transmittedhelminth-infections. Acesso em: 10 jan. 2021.

WORLD HEALTH ORGANIZATION (WHO). Ending the neglect to attain the Sustainable Development Goals: a road map for neglected tropical diseases 2021-2030. 2020b. Disponível em: https://www.who.int/publications/i/item/WHO-UCN-NTD-2020.01. Acesso em: 11 jan. 2021.

Recebido em março de 2021. Aprovado em julho de 2020.

Revisão gramatical realizada por: Kizie Pontes

E-mail: kiziepontes@gmail.com 